\title{
Prepulse inhibition of the startle eyeblink as an indicator of temporal summation
}

\author{
TERRY D. BLUMENTHAL \\ Wake Forest University, Winston-Salem, North Carolina
}

\begin{abstract}
The inhibition of the human startle eyeblink response was assessed in three experiments in which the duration of the prepulse was manipulated. In all cases, inhibition of startle was more pronounced as prepulse duration increased from 6 to $50 \mathrm{msec}$. Inhibition of startle amplitude for single prepulses was not significantly different from that for paired prepulses (Experiment 1), but inhibition was more pronounced as prepulse intensity increased (Experiment 3). Varying the interval between prepulse offset and startle-stimulus onset had no significant effect on inhibition (Experiment 2). These data demonstrate the sensitivity of startle inhibition to prepulse duration, and suggest that this response system can be used to evaluate early temporal summation in the auditory system.
\end{abstract}

The purpose of the present study was to investigate the process of temporal summation in the auditory system by measuring prepulse modification of the startle reflex. Temporal summation is a basic form of processing wherein the effect of sensory input occurring within some time window is added to that of previous input, so that the effectiveness of stimulation increases as either the number or the duration of stimuli increases (Penner, 1978; Zwislocki, 1969). This summation reaches asymptote after a certain amount of time has passed since the first input, and this defines the window of summation, or the critical interval of the summating mechanism.

Temporal summation in the auditory system has been investigated using psychophysical scaling in humans (Zwislocki, 1969), single-unit responding in animals (Gersuni, 1971), and startle-reflex elicitation in both animals (Marsh, Hoffman, \& Stitt, 1973) and humans (Blumenthal \& Berg, 1986a). The startle response is a brainstem reflex that is present in a wide variety of animal species (Davis, 1984), and that can be elicited by acoustic, visual, tactile, and electrical stimuli (Anthony, 1985; Graham, 1979; Hoffman \& Ison, 1980; Yeomans \& Cochrane, 1993). Using either single stimuli varying in duration or pairs of brief stimuli varying in interstimulus interval (ISI), the elicitation of the startle response has been used to illustrate temporal summation in adult humans, both within a single sensory modality (Blumenthal \& Berg, 1986a; Blumenthal \& Goode, 1991) and across modalities (Plant \& Hammond, 1989). Temporal summation has also been demonstrated with single and paired stimuli using the startle reflex in newborn infants

This research was partially supported by a grant from the Research and Creative Activities Council, Wake Forest University. The author would like to thank Christopher Goode for his assistance. Correspondence should be addressed to T. D. Blumenthal, Department of Psychology, Wake Forest University, Box 7778 Reynolda Station, Winston-Salem, NC 27109 (e-mail: blumen@wfu.edu).
(Blumenthal, Avendano, \& Berg, 1987) and in 16-weekold infants (Anthony, Zeigler, \& Graham, 1987). The critical interval over which temporal summation occurs is about $20-50 \mathrm{msec}$ for the human startle response. This is considerably less than the critical interval for loudness summation of about $200 \mathrm{msec}$ that is usually found with psychophysical techniques using both near-threshold and suprathreshold acoustic stimuli (Gelfand, 1990). Further, the critical interval of temporal summation found with the startle reflex is longer for infants than it is for adults (Blumenthal et al., 1987), and infants are less sensitive to very brief stimuli.

A startle response elicited by a stimulus in any sensory modality can be modified by a brief, low-intensity stimulus, called a prepulse, presented $30-500 \mathrm{msec}$ before the startle-eliciting stimulus (Graham, 1975). The extent of reflex modification is determined by the physical parameters of the prepulse (Anthony, 1985; Hoffman \& Ison, 1980). A prepulse is effective in modifying the response to a startle-eliciting stimulus, regardless of whether the two stimuli are in the same sensory modality or in different modalities (Blumenthal \& Gescheider, 1987; Graham, 1980). The startle response acts as an "interrupt" (Graham, 1980), and its inhibition by a prepulse is due to the protection of early processing of the prepulse, which reduces the impact of the interrupting startle stimulus.

As prepulse duration increases, the prepulse becomes more effective at inhibiting the startle response (Blumenthal, 1989; Dykman \& Ison, 1979; Mansbach \& Geyer, 1991). Harbin and Berg (1983) presented prepulses at durations of 20 and $200 \mathrm{msec}$, at stimulus onset asynchronies (SOAs) of 80-620 msec, before a startleeliciting puff of air lateral to the eye. They found that longer prepulses were more effective inhibitors than were shorter prepulses, and concluded that the effect of prepulse duration on reflex inhibition can best be explained "as resulting from the summating influence of the two transients which are becoming progressively 
more independent as they are separated in time" (Harbin \& Berg, 1983, p. 609).

The neurological pathways underlying both the elicitation and the modification of the startle reflex have been described in animal models (Davis, Gendelman, Tischler, \& Gendelman, 1982; Swerdlow \& Geyer, 1993). Prepulse modification of startle has been shown to be determined by activity in a part of the midbrain called the pedunculopontine tegmental area (PPTg; Swerdlow \& Geyer, 1993). This area projects to the nucleus reticularis pontis caudalis (nRPC), which is considered to be the area in the pons where the startle response is initiated (Davis, 1984). Activation of the nRPC produces startle responses, and activation of the PPTg inhibits these startle responses. If the present experiments show that prepulse inhibition of startle can be affected by the duration of the prepulse, this would suggest that the PPTg influence on the startle center can be used as a means of assessing temporal summation.

In the present series of experiments, prepulse durations in the range of 6-100 msec were used to assess temporal summation. In addition, other stimulus parameters that have been shown to influence startle modification were also manipulated. These included comparing single prepulses with pairs of brief prepulses, to assess the differential contributions of transient (onset and offset) and sustained (steady-state) stimulus components (Experiment 1), investigating the effects of prepulses at a range of SOAs and ISIs (Experiment 2); and investigating the effects of prepulses at a range of intensities (Experiment 3). One prediction was that increasing prepulse duration within a relatively narrow range would increase startle inhibition, demonstrating temporal summation. A second prediction was that the summation of two transients, as in a pair of brief prepulses, would have the same effect as the summation of one onset transient and a longer steady-state portion of a single stimulus. This prediction derives from the hypothesis that prepulse inhibition of startle is based on the transient aspects of the prepulse (Graham \& Murray, 1977). A third prediction was that prepulse duration would have an effect on startle inhibition that is independent of variations of ISI between prepulse offset and startlestimulus onset, within a narrow range. Since the three variables of prepulse duration, SOA, and ISI (between prepulse offset and startle-stimulus onset) have two degrees of freedom $(d f)$, varying prepulse duration while holding SOA constant causes variations in ISI. By varying two of these parametrically, the impact of each can be assessed. A fourth prediction was that a more intense prepulse would be a more effective inhibitor of startle, as shown by Blumenthal and Creps (1994), among others.

\section{EXPERIMENT 1}

\section{Method}

Subjects. Subjects were 11 male and 10 female college undergraduates, with an average age of 19 years, 7 months (range $=18$ years, 6 months -21 years, 11 months). These subjects, who were selected from a list of students who had volunteered to participate in psychology experiments for course credit, all reported good health at the time of testing, and none had a history of hearing loss.

Stimuli. Startle stimuli consisted of $85 \mathrm{~dB}(\mathrm{~A})$ broadband noise $(20 \mathrm{~Hz}-20 \mathrm{KHz})$, with a duration of $50 \mathrm{msec}$ and a rise/fall time of $0.1 \mathrm{msec}$. Prepulses consisted of $60-\mathrm{dB}(\mathrm{A})$ broadband noise, with a rise/fall time of $0.1 \mathrm{msec}$, presented in eight conditions, four involving single prepulses varying in duration $(6,20,50$, and $100 \mathrm{msec}$ ), and four involving pairs of $3-\mathrm{msec}$ prepulses with onset-to-onset intervals of $6,20,50$, and $100 \mathrm{msec}$. Prepulse lead time, from the onset of the single prepulse (or the first prepulse in a pair) to startle-stimulus onset, was $150 \mathrm{msec}$ in all cases. A control condition involved presenting the startle stimulus alone, with no prepulse.

Apparatus. Startle stimuli and prepulses were produced by separate Coulbourn S81-02 noise generators and gated through separate Coulbourn \$84-04 shaped rise/fall gates, the outputs of which were sent to a Coulbourn S82-24 audio mixer amplifier. The output of this amplifier was sent to a Yamaha M-35 stereo amplifier, which activated an Onkyo S-30 loudspeaker located $1.5 \mathrm{~m}$ in front of the subject. The timing and duration of the stimuli were controlled by a Macintosh SE computer and a MacPacq MP10 computer interface. Stimulus intensity was calibrated with a Quest Electronics 215 sound-level meter, held at the position of the subject's ear during the presentation of a steady-state stimulus, and a Fluke $8050 \mathrm{~A}$ digital multimeter, used to set the voltage of the input to the loudspeaker.

Responses were measured with miniature $\mathrm{Ag} / \mathrm{AgCl}$ electrodes (with 4-mm-diam contactors) filled with conducting paste, the raw EMG signal being sent to a Coulbourn S75-01 High Gain Bioamplifier, where it was amplified and filtered (passing 90-250 $\mathrm{Hz}$ ). The output of the Bioamplifier was sent to a Coulbourn S7601 contour-following integrator with a time constant of $10 \mathrm{msec}$ (Blumenthal, 1994), the output of which was digitally sampled every $1 \mathrm{msec}$ for $500 \mathrm{msec}$, beginning $150 \mathrm{msec}$ before startlestimulus onset, and displayed on the Macintosh SE computer.

Procedure. Before each session, the subject was required to sign an informed consent form and complete a health questionnaire. The skin below the left eye was cleaned with a cotton swab dipped in alcohol, and two recording electrodes were attached below the eye, on the skin covering the orbicularis oculi. A ground electrode was attached to the inner left forearm. The subject was taken into the testing room and asked to remain as still as possible. The procedure was then explained, and stimulus presentation began. Each subject received eight blocks of nine trials each, with each block containing one control trial and one trial in each of the prepulse conditions, presented in random order within a block. The intertrial-interval (ITI) range was $25-35 \mathrm{sec}$, and averaged $30 \mathrm{sec}$.

Data analysis. The amplitude, latency, and probability of the eyeblink response were measured from the integrated EMG sampled by the computer. Only responses with onsets occurring within $20-100 \mathrm{msec}$ of startle-stimulus onset were included, to eliminate nonreflexive responses. If the integrated EMG activity surpassed the baseline EMG activity (measured for $20 \mathrm{msec}$ after stimulus onset on each trial) within $20-100 \mathrm{msec}$ after startle-stimulus onset, a response onset was said to have occurred. Response latency was the time between startle-stimuius onset and response onset. The peak of the response was the maximum value within the scoring window of $20-150 \mathrm{msec}$ after startle-stimulus onset. Response amplitude was the difference between the EMG level at response onset and peak, measured in arbitrary analog-to-digital units and then converted to microvolts based on a calibration factor of $.45 \mu \mathrm{V}$ per arbitrary unit. Caution must be exercised when using $\mu \mathrm{V}$ values of startle-response amplitude in comparing results from different laboratories: Unless the recording, filtering, scoring, and calibration procedures are the same, $\mu \mathrm{V}$ in one laboratory may not correspond to $\mu \mathrm{V}$ in another laboratory. Thus, reporting response amplitudes in $\mu \mathrm{V}$ may be no more comparable 
across laboratories than reporting these measures in arbitrary units. However, the use of $\mu \mathrm{V}$ may give the mistaken impression that comparability is possible, and therefore the filtering and amplification of the EMG must be described in detail.

If the EMG signal during the response onset window (20$100 \mathrm{msec}$ after startle-stimulus onset) did not deviate from that present during the baseline period before startle-stimulus onset, a failure to respond was recorded. Response probability was calculated as the number of scorable responses that occurred, divided by the number of trials on which a response could have been scored, within each stimulus condition (see Blumenthal \& Goode, 1991, for more information regarding response quantification).

Data were analyzed in separate analyses of variance (ANOVAs) for each dependent variable, with conservative (GreenhouseGeisser) $d f$ applied. Follow-up comparisons were made with pairwise contrasts within a second ANOVA. When assessing the effect of a prepulse on startle responding, we first compared the response to the startle stimulus in the control (no-prepulse) condition with the response to the startle stimulus in each prepulse condition. If responding in the prepulse conditions is significantly different from responding in the control condition, we call this startle modification. Specifically, startle inhibition is illustrated by reduced response amplitude or probability, or by increased response latency, in the prepulse condition in comparison with the control condition. Changes in the opposite direction constitute startle facilitation. After determining the effect of each prepulse condition relative to the control condition, we assessed whether some prepulses were more effective startle modifiers than others, by comparing startle modification (i.e., the difference between responding on prepulse and control trials) in different prepulse conditions. These data analyses included the two within-subjects variables of prepulse duration/interval $(6,20,50$, or $100 \mathrm{msec})$ and prepulse number (single or paired). The average difference between responding on control and prepulse trials for each condition is presented in Figures 1-3.

\section{Results}

Response amplitude was reduced in all prepulse condtions, in comparison with the control condition $(p<.001$ in all cases; see Figure 1). Prepulse duration/interval had a significant effect $[F(3,60)=3.41, p<.05, \epsilon=.67]$, but neither the prepulse-number effect nor the duration/ interval by prepulse-number interaction reached significance. Increasing prepulse duration/interval from 6 to $20 \mathrm{msec}$ resulted in slightly more pronounced startle inhibition $[F(1,20)=4.02, p<.06]$, and increasing prepulse duration/interval from 6 to $50 \mathrm{msec}$ resulted in significantly more pronounced startle inhibition $[F(1,20)=$ $13.73, p<.01]$.

Response probability was reduced by the prepulse in all conditions ( $p<.025$ in all cases; see Figure 1$)$. The prepulse duration/interval effect was significant $[F(3,60)=$ $3.96, p<.025, \epsilon=.95]$, as was the effect of prepulse number $[F(1,20)=14.01, p<.01]$; the duration/interval $\times$ number interaction was also significant $[F(3,60)=$ $6.08, p<.01, \epsilon=.80]$. Response probability decreased (indicating greater inhibition) as the duration of a single prepulse increased from 6 to $20 \mathrm{msec}[F(1,20)=8.96$, $p<.01$ ] but increasing prepulse duration beyond $20 \mathrm{msec}$ had no further effect. Increasing the interval between prepulses in a pair from 6 to $50 \mathrm{msec}$ had no significant effect on response probability, but a pair of prepulses presented at a 100 -msec interval resulted in less
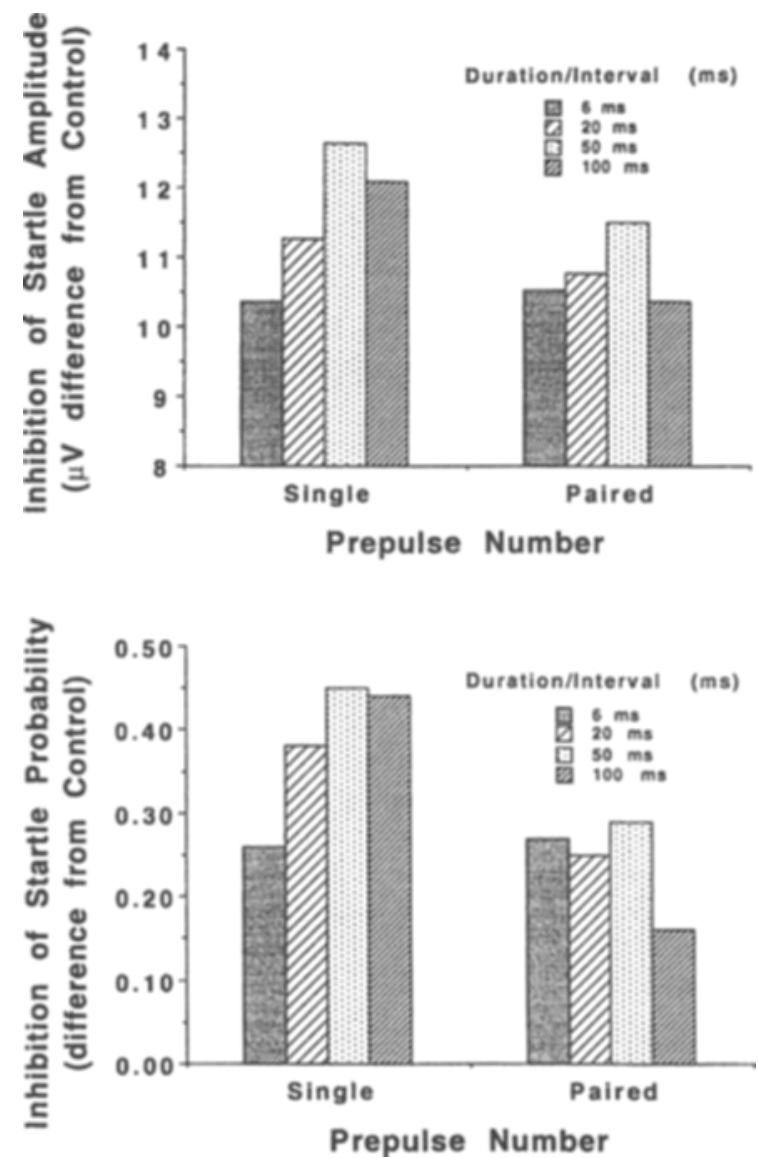

Figure 1. Inhibition of startle-response amplitude (top) and probability (bottom) as a function of prepulse duration, for single and paired prepulses.

inhibition than was found with a pair of prepulses at an interval of $6 \mathrm{msec}[F(1,20)=9.32, p<.01]$. Single prepulses caused more inhibition of response probability than did paired prepulses at times of 20,50 , and $100 \mathrm{msec}[F(1,20)=4.39,6.56$, and 26.77 , respectively, $p<.05]$.

Response latency was decreased (facilitated) by single prepulses with a duration of $20 \mathrm{msec}$, and by paired prepulses at intervals of 20,50 , and $100 \mathrm{msec}(p<.05$ in all cases). No significant effects of prepulse duration/ interval, prepulse number, or duration/interval $\times$ number interaction were found.

\section{Discussion}

The response-amplitude data of the present experiment support Harbin and Berg's (1983) conclusion that prepulse inhibition becomes more pronounced as the time is increased between onset and offset transients of a prepulse. When two transient prepulses were presented, with no steady-state portion between them, prepulse inhibition of startle amplitude increased as the time between the transients increased from 6 to $50 \mathrm{msec}$. 
Further, single prepulses were no more effective as startle-amplitude inhibitors than were pairs of prepulses, suggesting that the steady-state portion of the single prepulse made no significant contribution to startleamplitude inhibition. The power of the present study to detect an effect of prepulse number on responseamplitude inhibition was 90 , suggesting that the failure to find a significant effect of the prepulse-number variable was due to a true absence of an effect, rather than to a lack of power. However, the response-probability data of the present experiment do not support Harbin and Berg's conclusion, since increasing the time between two transients did not affect the prepulse inhibition of response probability, while increasing the duration of a single prepulse increased probability inhibition. The steady-state portion of the prepulse reduced response probability but not response amplitude, supporting the possible independence of startle amplifier (amplitude) and trigger (probability) mechanisms proposed by Blumenthal and Berg (1986b). The present data also show that a pair of prepulses $100 \mathrm{msec}$ apart constituted a less effective inhibitor than a pair of prepulses separated by a 6- or 50-msec interval. At $100 \mathrm{msec}$, the second prepulse may be outside the summation window, so it cannot affect the response.

\section{EXPERIMENT 2}

An alternative explanation for the apparent effects of prepulse duration on startle modification shown in Experiment 1 is that as prepulse duration increases at a given SOA, so the time between prepulse offset and startle-stimulus onset decreases. That is, given the three variables of SOA, prepulse duration, and ISI, only two $d f$ are available. Changing prepulse duration while holding SOA constant results in variations of ISI. Stitt, Hoffman, and Marsh (1976) showed that the startle reflex of the rat is affected by the time between the offset of a steady-state sound and the onset of a startle-eliciting noise, at intervals of less than $16 \mathrm{msec}$. However, they found no significant differences between intervals of $16-250$ msec (in their Experiment 1), with startle inhibition across this range of intervals. Stitt, Hoffman, Marsh, and Boskoff (1974) showed that the offset of an acoustic background inhibited startle responding in the rat, and this inhibition was equivalent when the offset preceded startle-stimulus onset by either 64 or $250 \mathrm{msec}$.

A second experiment was designed to evaluate the hypothesis that the effects attributed to increasing prepulse duration in Experiment 1 were actually due to variations in ISI (prepulse offset to startle-stimulus onset). Prepulses were presented at three durations, with each duration presented at three ISIs, selected to span the range of ISIs within which apparent temporal-summation effects were found in Experiment 1. Three of these prepulses also involved the three durations presented at the same SOA, for comparison with the earlier data. If the temporal-summation findings of Experiment 1 were due to variations in ISI rather than to variations in prepulse duration, that effect should be revealed in this second experiment.

\section{Method}

Subjects. The subjects were 4 male and 19 female college undergraduates with an average age of 19 years (range $=17$ years, 9 months-22 years, 4 months), who were selected in the same way as those of Experiment 1.

Stimuli. The startle stimulus was an $85-\mathrm{dB}(\mathrm{A})$ broadband noise $(20 \mathrm{~Hz}-20 \mathrm{KHz})$, with a $0.1-\mathrm{msec}$ rise/fall time and a 50 -msec duration. Prepulses were $60-\mathrm{dB}(\mathrm{A})$ broadband noise $(20 \mathrm{~Hz}-$ $20 \mathrm{KHz}$ ), with a $0.1-\mathrm{msec}$ rise/fall time, presented in nine conditions-namely, a 6-msec-duration prepulse presented at SOAs of 106,136 , and $150 \mathrm{msec} ; \mathrm{a} 20$-msec-duration prepulse presented at SOAs of 120,150 , and $164 \mathrm{msec}$; and a 50 -msec-duration prepulse presented at SOAs of 150, 180, and $194 \mathrm{msec}$. In this way, each prepulse duration was presented at ISIs (prepulse offset to startlestimulus onset) of 100,130 , and $144 \mathrm{msec}$ (i.e., the ISI range which characterized the range of prepulse durations that showed temporal-summation effects in Experiment 1). Two trials per block involved the control condition of an $85-\mathrm{dB}(\mathrm{A})$ startle stimulus presented alone.

Apparatus and Procedure. Apparatus, procedure, and data analysis were the same as in Experiment 1, with the following exceptions: Each subject received seven blocks of 11 trials each, with each block containing 2 startle-stimulus-alone control trials and 1 trial in each of the nine prepulse conditions, presented in random order within a block. ITI averaged $25 \mathrm{sec}$, randomly ranging from 20 to $30 \mathrm{sec}$. For data analyses, responding on the 2 control trials was averaged together within each block, and prepulse effects were calculated for each dependent variable by taking the difference between this average control value and responding in each prepulse condition. A $3 \times 3$ (prepulse duration $\times$ ISI) ANOVA was then conducted.

\section{Results}

Prepulses inhibited response amplitude in all cases $(p<.01)$. In the $3 \times 3$ ANOVA, prepulse duration had a significant effect $[F(2,44)=6.37, p<.01, \epsilon=.82]$, but neither the main effect of ISI nor the interaction between these two variables reached significance (see Figure 2). Increasing prepulse duration from 6 to $20 \mathrm{msec}$ resulted in more pronounced inhibition of startle $[F(1,22)=$ $5.19, p<.05]$, but increasing prepulse duration to $50 \mathrm{msec}$ had no further effect.

Prepulses inhibited response probability in all cases $(p<.05)$. In the $3 \times 3$ ANOVA, prepulse duration had a significant effect $[F(2,44)=8.39, p<.01, \epsilon=.84]$, but neither the main effect of ISI nor the interaction between these two variables reached significance (see Figure 2). Increasing prepulse duration from 6 to $20 \mathrm{msec}$ resulted in more inhibition of startle $[F(1,22)=5.92, p<.05$, and increasing prepulse duration from 20 to $50 \mathrm{msec}$ caused further inhibition $[F(1,22)=4.86, p<.05]$.

The prepulse inhibited response latency in the 20 msec-duration $\times 100-\mathrm{msec}$ ISI condition $[F(1,22)=$ $2.54, p<.05]$, but not in any other condition. Prepulse duration and ISI had no differential effect on response latency.

\section{Discussion}

These data show that variations in prepulse duration influence the degree of prepulse inhibition of startle, in- 

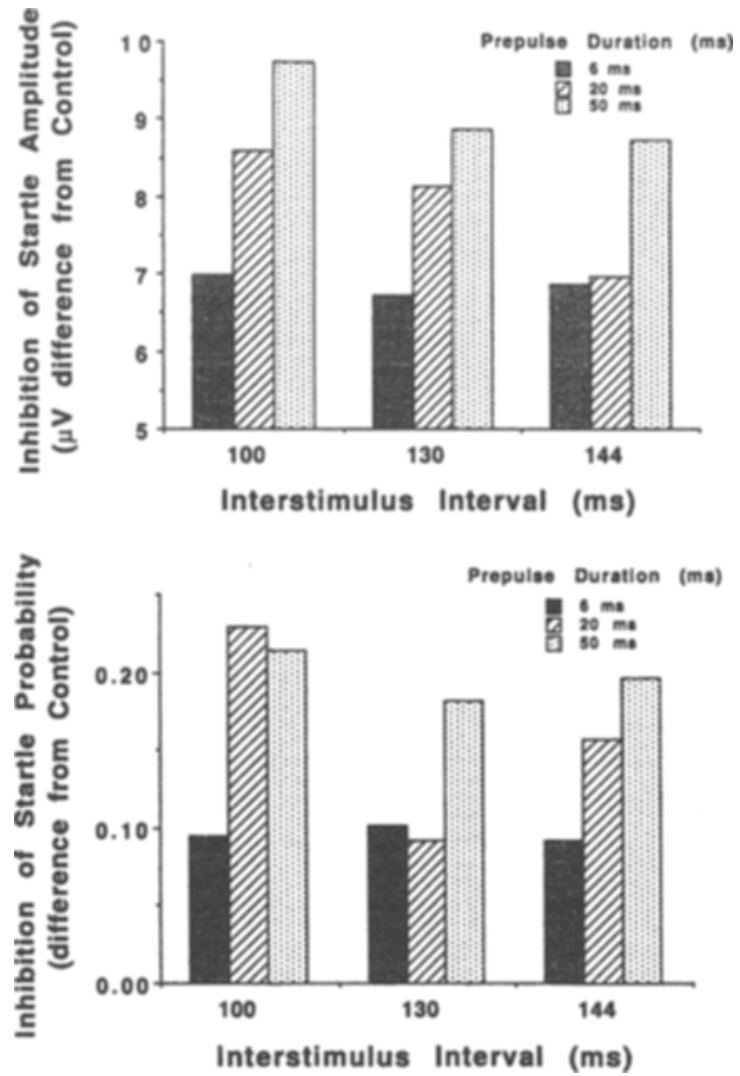

Figure 2. Inhibition of startle-response amplitude (top) and probability (bottom) as a function of prepulse duration, for prepulses with offsets occurring 100, 130, and 144 msec before startle-stimulus onset.

dependent of the interval between prepulse offset and startle-stimulus onset, at least in the range of intervals used here. Since this range of offset-to-onset intervals is identical to that found in the effective duration range of Experiment 1, these data suggest that the effects in both of these experiments are due to variations in prepulse duration, not to variations in ISI.

\section{EXPERIMENT 3}

Prepulse inhibition increases as the intensity of the prepulse increases (Blumenthal \& Creps, 1994; Graham \& Murray, 1977). A third experiment was designed to investigate the relationship between prepulse intensity and prepulse duration in the inhibition of startle.

\section{Method}

Subjects. The subjects were 4 male and 9 female college undergraduates with an average age of 19 years, 3 months (range $=$ 18 years, 4 months -20 years, 11 months), who were selected in the same way as those of Experiments 1 and 2.

Stimuli. The startle stimulus was an $85-\mathrm{dB}(\mathrm{A})$ broadband noise $(20 \mathrm{~Hz}-20 \mathrm{KHz})$, with a $0.1-\mathrm{msec}$ rise/fall time and a $50-\mathrm{msec}$ duration. Prepulses were $40-, 50-$, or $60-\mathrm{dB}(\mathrm{A})$ broadband noise $(20 \mathrm{~Hz}-20 \mathrm{KHz})$, with a $0.1-\mathrm{msec}$ rise/fall time and durations of $6,20,50$, or $100 \mathrm{msec}$. Lead time (prepulse onset to startle-stimulus onset) was 150 msec. A control condition with an $85-\mathrm{dB}$ (A) startle stimulus presented alone was also used.

Apparatus and Procedure. Apparatus, procedure, and data analysis were the same as for Experiment 1, with the following exceptions. Startle stimuli and prepulses were produced by three Coulbourn noise generators gated through four Coulbourn shaped rise/fall gates, amplified and presented in the same way as those of Experiment 1. Each subject received six trial blocks of 13 trials each, with each trial block containing 1 startle-stimulus-alone control trial and 1 trial in each of the 12 prepulse conditions, presented in random order within a trial block. ITI averaged $20 \mathrm{sec}$ (randomly ranging from 15 to $25 \mathrm{sec}$ ). Data analyses included two within-subjects variables-prepulse duration $(6,20,50$, or $100 \mathrm{msec})$ and prepulse intensity $(40,50$, or $60 \mathrm{~dB})$.

\section{Results}

Response amplitude was inhibited by prepulses in all conditions ( $p<.001$ in all cases; see Figure 3$)$. Inhibition of response amplitude was significantly affected by both prepulse duration $[F(3,36)=7.45, p<.01, \epsilon=.53]$ and prepulse intensity $[F(2,24)=13.73, p<.01, \epsilon=$ $.60]$, but the two variables did not interact. Increasing prepulse duration from 6 to $20 \mathrm{msec}$ resulted in more pronounced prepulse inhibition $[F(1,12)=12.41, p<$ $.01]$, but increasing prepulse duration beyond $20 \mathrm{msec}$
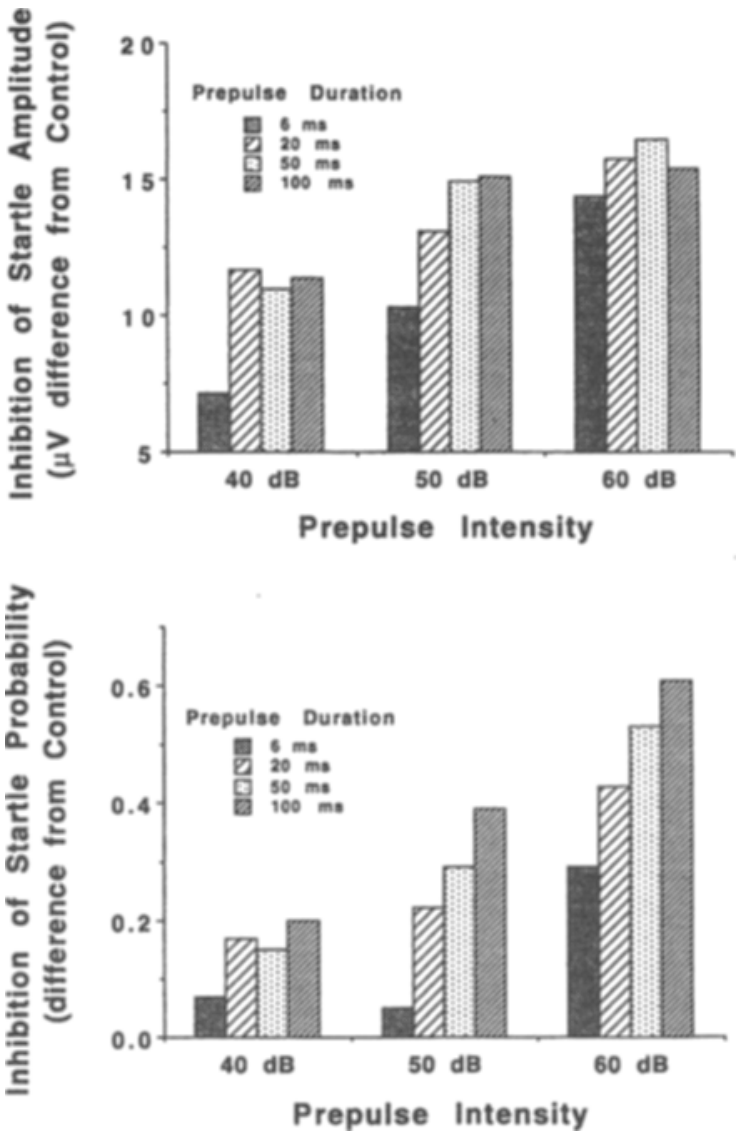

Figure 3. Inhibition of startle-response amplitude (top) and probability (bottom) as a function of prepulse duration, for $40-, 50-$, and 60-dB(A) prepulses. 
had no greater effect. Increasing prepulse intensity from 40 to $50 \mathrm{~dB}$ resulted in more pronounced prepulse inhibition $[F(1,12)=16.33, p<.01]$, as did increasing prepulse intensity from 50 to $60 \mathrm{~dB}[F(1,12)=7.54, p<.025]$.

Response probability was inhibited by the prepulses $(p<.05)$ in all cases except three: the 6-msec prepulses at 40 and $50 \mathrm{~dB}$, and the $50-\mathrm{msec}$ prepulse at $40 \mathrm{~dB}$ (see Figure 3). Inhibition of response probability was significantly affected by prepulse duration $[F(3,36)=12.75$, $p<.01, \epsilon=.66]$ and by prepulse intensity $[F(2,24)=$ $40.77, p<.01, \epsilon=.71]$, but the two variables did not interact. Increasing prepulse duration from 6 to $20 \mathrm{msec}$ resulted in more pronounced inhibition of response probability $[F(1,12)=7.15, p<.05]$, as did increasing prepulse duration from 20 to $100 \mathrm{msec}[F(1,12)=$ $13.76, p<.01]$. Inhibition of response probability was more pronounced as prepulse intensity was increased from 40 to $50 \mathrm{~dB}[F(1,12)=11.06, p<.01]$, and from 50 to $60 \mathrm{~dB}[F(1,12)=47.38, p<.01]$.

Response latency was decreased (facilitated) by the $40-\mathrm{dB}$ prepulse at a 6 -msec duration $[F(1,12)=19.91$, $p<.01]$, but prepulses had no effect on latency at any other duration or intensity combination.

\section{Discussion}

As was the case in Experiments 1 and 2, increasing prepulse duration caused more pronounced inhibition of startle amplitude and probability. In agreement with previous research (Blumenthal \& Creps, 1994; Graham \& Murray, 1977), increasing prepulse intensity caused the prepulses to more effectively inhibit startle. However, prepulse duration and intensity did not interact significantly.

\section{GENERAL DISCUSSION}

In all three experiments, increasing the duration of an acoustic prepulse resulted in greater inhibition of the amplitude and probability of the startle eyeblink response. These results show that the modification of the acoustic startle response can be affected by temporal summation of the prepulse. Further, the absence of interactions between prepulse duration and other variables when analyzing inhibition of startle amplitude shows that, in the ranges tested here, this temporal summation is independent of prepulse number, ISI, and intensity. Effects of prepulse duration on the inhibition of response probability were also independent of ISI and prepulse intensity. However, the data of Experiment 1 show that response probability was not differentially affected by increasing the interval between two pulses in a pair, while inhibition of response amplitude was affected by this manipulation.

Prepulse inhibition of startle is affected by the duration of the prepulse, making startle-reflex inhibition a useful tool in the assessment of temporal summation. The investigation of temporal summation can be useful in quantifying hearing loss (Florentine, Fastl, \& Buus, 1988; Stephens, 1976), and adding prepulse inhibition to the list of methods available could be helpful in this clin- ical endeavor. Given its sensitivity to stimulus manipulations, the startle response has been proposed as a sensory assessment tool, especially in audiological assessment of infants and handicapped children and adults (Anday, Cohen, Kelley, \& Hoffman, 1988; Reiter, Goetzinger, \& Press, 1981). The utility of the startle response in the assessment of sensory abilities derives from the fact that it is a graded reflex, with variations in response amplitude, probability, and latency determined either by variations in the eliciting stimulus itself or by variations in prepulses that precede the eliciting stimulus. Reflex modification can provide an objective and reliable assessment of auditory threshold, without requiring cooperation, motivation, training, or attention on the part of the subject, and this modification is not dependent upon previous conditioning.

Studies of temporal summation can also help to identify the mechanisms underlying the processing of stimuli. Zwislocki $(1969,1983)$ proposed a neural mechanism for temporal summation, involving a neural volley causing a change in the postsynaptic potential, with this change persisting for some time and then decaying. If new neural input occurs before the postsynaptic resting level is reached, the new input will be added to the residual potential caused by previous input. Decay continues to occur, but if the input is occurring faster than the time constant of the postsynaptic membrane, further input will add to the residual potential shift, increasing the total amount of postsynaptic potential change. At some point, the postsynaptic membrane will reach some maximum level, or saturation, and continued input beyond this point will have no further effect. Demonstrating that prepulse inhibition is influenced by temporal summation may assist in the study of the neural mechanisms underlying inhibitory influences of the tegmental startleinhibition center (Swerdlow \& Geyer, 1993) on the pontine startle activation center (Davis et al., 1982).

In the early stages of stimulus processing, a distinction can be made between stimulus detection (transient, change, onset, or offset) and stimulus identification (sustained, steady-state stimulus parameters; Berg, 1985). On the basis of the identification of transient (short time constant) and sustained (long time constant) neural types in the auditory system (Gersuni, 1971; Gersuni et al., 1971), Graham (1979) has suggested that these transient and sustained stimulus parameters may be processed by parallel neurological systems. Transient and sustained systems in the auditory pathway are analogous to $\mathrm{Y}$ cells and $\mathrm{X}$ cells (retinal ganglion cells) in the visual system (Schwartz \& Loop, 1984), and to Pacinian and non-Pacinian systems in the vibrotactile modality (Gescheider, Hoffman, Harrison, Travis, \& Bolanowski, 1994). Several researchers (Graham \& Murray, 1977; Ison, 1978) state that startle elicitation is due to the activation of the transient system. Graham and Murray argue that startle-reflex inhibition by a prepulse is also due to transient-system activity, while Ison believes that sustained-system activity is responsible for this inhibition. Blumenthal and Levey (1989) argue that transient- 
system activation may determine acoustic startle-reflex inhibition, while sustained-system activation may determine acoustic startle-reflex facilitation.

The data of Experiment 1 show that the inhibition of startle amplitude is accomplished predominantly by the transient aspects of the prepulse, since a single prepulse was no more effective than a pair of prepulses with less total energy. Prepulse onset activates the transient system, and this transient-system activation is greater for stimuli of longer duration, up to a point. This would be the case if rapid temporal summation of energy occurred in the transient system. The transient system is often considered to be insensitive to stimulus duration, but it may be the case that this system is simply less sensitive to stimulus duration than is the sustained system. Therefore, the transient system may show temporal summation, but only for a brief time. In fact, Gersuni (1971, p. 106) found that transient-system neurons are sensitive to changes in stimulus energy occurring for up to $20 \mathrm{msec}$, illustrating the ability of the transient system to show temporal summation within a narrow window. The data of the present experiments support the notion that prepulse-inhibition effects are due to the activity of a rapidly summating transient-sensitive system, in agreement with Blumenthal and Levey (1989) and Graham and Murray (1977).

Other researchers (Plant \& Hammond, 1989) state that the distinction between transient and sustained systems may not be relevant to startle responding, since the distinction between transient and sustained neural units is most pronounced at the firing threshold of these units. At stimulus intensities above threshold, the differences between the two neuron types decrease, with some transient neurons showing a more tonic discharge pattern than others. However, some transient neurons maintain their phasic discharge pattern even for stimuli well above threshold (Gersuni, 1971, p. 89). Further, singleunit firing-threshold values ranged from -20 to $+70 \mathrm{~dB}$ (SPL) for transient neurons, and from -30 to $+60 \mathrm{~dB}$ (SPL) for sustained neurons (Gersuni, 1971). On the basis of these single-unit data, we feel that the distinction between transient and sustained systems in startle research is valid, and that this distinction may be more evident at lower stimulus intensities, such as those found with prepulses, than at higher stimulus intensities, such as those found with startle-eliciting stimuli.

These data show that prepulse inhibition of startle is affected by many of the same stimulus variables, such as stimulus intensity, duration, and number, that affect the elicitation of the startle reflex itself (Blumenthal, 1988; Blumenthal \& Berg, 1986a, 1986b). In fact, the temporalsummation window of $20-50 \mathrm{msec}$ found for startleamplitude inhibition in the present experiments is similar to the temporal-summation window for startle-reflex elicitation (Blumenthal et al., 1987; Blumenthal \& Berg, 1986a). Therefore, prepulse inhibition of startle can be used as a sensitive measure of acoustic stimulus processing, at stimulus intensities well below those needed to elicit the startle reflex. This broadens the range of potential applications of this prepulse-inhibition technique.

\section{REFERENCES}

Anday, E. K., Cohen, M. E., Kelley, N. E., \& Hoffman, H. S. (1988). Reflex modification audiometry: Assessment of acoustic sensory processing in the term neonate. Pediatric Research, 23, 357-363.

ANTHONY, B. J. (1985). In the blink of an eye: Implications of reflex modification for information processing. In P. K. Ackles, J. R. Jennings, \& M. G. H. Coles (Eds.), Advances in psychophysiology (Vol. 1, pp. 167-218). Greenwich, CT: Jai Press.

Anthony, B. J., Zeigl.er, B. L., \& Graham, F. K. (1987). Stimulus duration as an age-dependent factor in reflex blinking. Developmental Psychobiology, 20, 285-297.

BERG, K. M. (1985). Temporal masking level differences for transients: Further evidence for a short-term integrator. Perception \& Psychophysics, 37, 397-406.

Blumenthal, T. D. (1988). The startle response to acoustic stimuli near startle threshold: Effects of stimulus rise and fall time, duration, and intensity. Psychophysiology, 25, 607-611.

Blumenthal, T. D. (1989, March). Differential effects of acoustic prepulses on the inhibition of startle reflex amplitude and probability. Paper presented at the Southeastern Psychological Association Convention, Washington, DC.

Blumenthal, T. D. (1994). Signal attenuation as a function of integrator time constant and signal duration. Psychophysiology, 31, 201-203.

Blumenthal, T. D., Avendano, A., \& Berg, W. K. (1987). The startle response and auditory temporal summation in neonates. Journal of Experimental Child Psychology, 44, 64-79.

Blumenthal, T. D., \& BeRG, W. K. (1986a). The startle response as an indicator of temporal summation. Perception \& Psychophysics, 40, 62-68.

Blumenthal, T. D., \& BerG, W. K. (1986b). Stimulus rise time, intensity, and bandwidth effects on acoustic startle amplitude and probability. Psychophysiology, 23, 635-641.

Blumenthal, T. D., \& CRePs, C. L. (1994). Normal startle responding in psychosis-prone college students. Personality \& Individual Differences, 17, 345-355.

Blumenthal, T. D., \& Gescheider, G. A. (1987). Modification of the acoustic startle response by a tactile prepulse: Effects of stimulus onset asynchrony and prepulse intensity. Psychophysiology, 24, 320-327.

Blumenthal, T. D., \& Goode, C. T. (1991). The startle eyeblink response to low intensity acoustic stimuli. Psychophysiology, 28, 296306.

Blumenthal, T. D., \& Levey, B. J. (1989). Prepulse rise time and startle reflex modification: Different effects for discrete and continuous prepulses. Psychophysiology, 26, 158-165.

Davis, M. (1984). The mammalian startle response. In R. C. Eaton (Ed.), Neural mechanisms of startle behavior (pp. 287-351). New York: Plenum.

Davis, M., Gendelman, D. S., Tischler, M. D., \& Gendelman, P. M. (1982). A primary acoustic startle circuit: Lesion and stimulation studies. Journal of Neuroscience, 2, 791-805.

DYKMAN, B. M., \& ISON, J. R. (1979). Temporal integration of acoustic prestimulation and reflex inhibition in rats and humans. Journal of Comparative \& Physiological Psychology, 93, 939-945.

Florentine, M., FASTl, H., \& BuUs, S. (1988). Temporal integration in normal hearing, cochlear impairment, and impairment simulated by masking. Journal of the Acoustical Society of America, 84, 195 203.

GELFAND, S. A. (1990). Hearing: An introduction to psychological and physiological acoustics (2nd ed.). New York: Dekker.

GERSUNI, G. V. (1971). Temporal organization of the auditory function. In G. V. Gersuni (Ed.), Sensory processes at the neuronal and behavioral levels (pp. 85-114). New York: Academic Press.

Gersuni, G. V., Altman, J. A., Maruseva, A. M., Radionova, E. A., 
Ratnikova, G. I., \& Vartanian, I. A. (1971). Functional classification of neurons in the inferior colliculus of the cat according to their temporal characteristics. In G. V. Gersuni (Ed.), Sensory processes at the neuronal and hehavioral levels (pp. 157-180). New York: Academic Press.

Gescheider, G. A., Hoffman, K. E., Harrison, M. A., Travis, M. L., \& BolanowsKI, S. J. (1994). The effects of masking on vibrotactile temporal summation in the detection of sinusoidal and noise signals. Journal of the Acoustical Society of America, 95, 1006-1016.

Graham, F. K. (1975). The more or less startling effects of weak prestimulation. Psychophysiology, 12, 238-248.

Graham, F. K. (1979). Distinguishing among orienting, defense, and startle reflexes. In H. D. Kimmel, E. H. van Olst, \& J. F. Orlebeke (Eds.), The orienting reflex in humans (pp. 137-167). Hillsdale, NJ: Erlbaum.

Graham, F. K. (1980). Control of reflex blink excitability. In R. F. Thompson, L. H. Hicks, \& V. B. Shvyrkov (Eds.), Neural mechanisms of goal-directed behavior and learning (pp. 511-519). New York: Academic Press.

Graham, F. K., \& Murray, G. M. (1977). Discordant effects of weak prestimulation on magnitude and latency of the reflex blink. Physiological Psychology, 5, 108-114.

Harbin, T. J., \& BERG, W. K. (1983). The effects of age and prestimulus duration upon reflex inhibition. Psychophysiology, 20, 603-610.

HoffMan, H. S., \& ISON, J. R. (1980). Reflex modification in the domain of startle: I. Some empirical findings and their implications for how the nervous system processes sensory input. Psychological Review, 87, 175-189.

IsoN, J. R. (1978). Reflex inhibition and reflex elicitation by acoustic stimuli differing in abruptness of onset and peak intensity. Animal Learning \& Behavior, 6, 106-110.

MansBach, R. S., \& Geyer, M. A. (1991). Parametric determinants in pre-stimulus modification of acoustic startle: Interaction with ketamine. Psychopharmacology, 105, 162-168.

Marsh, R., Hoffman, H. S., \& StiTt, C. L. (1973). Temporal integration in the acoustic startle reflex of the rat. Journal of Comparative \& Physiological Psychology, 82, 507-511.

PENNER, M. J. (1978). A power law transformation resulting in a class of short-term integrators that produce time-intensity trades for noise bursts. Journal of the Acoustical Society of America, 63. 195-201.

Plant, Y., \& Hammond, G. R. (1989). Temporal integration of acoustic and cutaneous stimuli shown in the blink reflex. Perception \& Psychophisics, 45, 258-264.

Reiter, L. A., Goetzinger, C. P., \& Press, S. E. (1981). Reflex modulation: A hearing test for the difficult-to-test. Journal of Speech \& Hearing Disorders, 24, 262-266

SchWARTZ, S. H., \& LoOp, M. S. (1984). Effect of duration on detection by the chromatic and achromatic systems. Perception \& PSychophysics, 36, 65-67.

STEPHENS, S. D. G. (1976). Auditory temporal summation in patients with central nervous system lesions. In S. D. G. Stephens (Ed.), Disorders of auditory function (Vol. 2, pp. 231-241). New York: Academic Press.

StitT, C. L., Hoffman, H. S., \& MarSH, R. R. (1976). Interaction versus independence of the startle modification processes in the rat Journal of Experimental Psychology: Animal Behavior Processes, 2, 260-265.

Stitt, C. L., Hoffman, H. S., Marsh, R. R., \& Boskoff, K. J. (1974). Modification of the rat's startle reaction by an antecedent change in the acoustic environment. Journal of Comparative \& Physiological Psychology, 86, 826-836

Swerdlow, N. R., \& Geyer, M. A. (1993). Prepulse inhibition of acoustic startle in rats after lesions of the pedunculopontine tegmental nucleus. Behavioral Neuroscience, 107, 104-117.

Yeomans, J. S., \& Cochrane, K. A. (1993). Collision-like interactions between acoustic and electrical signals that produce startle reflexes in reticular formation sites. Brain Research, 617, 320-328.

ZwISLOCKI, J. J. (1969). Temporal summation of loudness: An analysis. Journal of the Acoustical Society of America, 46, 431-441.

ZwISLOCKI, J. J. (1983). Group and individual relations between sensation magnitudes and their numerical estimates. Perception \& Psychophysics, 33, 460-468.

(Manuscript received July 5, 1994; revision accepted for publication November 25,1994 .) 